\title{
Film Cooling in Rocket Nozzles
}

\author{
Sandra Ludescher and Herbert Olivier
}

\begin{abstract}
In this project supersonic, tangential film cooling in the expansion part of a nozzle with rocket-engine like hot gas conditions was investigated. Therefore, a parametric study in a conical nozzle was conducted revealing the most important influencing parameter on film cooling for the presented setup. Additionally, a new axisymmetric film cooling model and a method for calculating the cooling efficiency from experimental data was developed. These models lead to a satisfying correlation of the data. Furthermore, film cooling in a dual-bell nozzle performing in altitude mode was investigated. The aim of these experiments was to show the influence of different contour inflection geometries on the film cooling efficiency in the bell extension.
\end{abstract}

\section{Motivation}

Film cooling is a cooling technique often used in rocket engines for thermally less stressed components. In regions of higher thermal loads it is used in combination with other cooling techniques. It is based on a liquid or gaseous coolant film that is injected at the wall and creates a protective layer between hot gas and structure. Due to its reusability and relatively simple system integration, film cooling is an promising cooling technique also for future generation rocket engines.

For about fifty years a lot of studies on film cooling were conducted [6, 10]. However, especially for the application of film cooling in the supersonic hot gas flow of a nozzle, which is characterized by high stagnation temperatures and pressures as well as high Mach numbers, the most influencing parameters are neither identified nor understood. Therefore, the aim of this project is to provide a better understanding

\footnotetext{
S. Ludescher · H. Olivier ( $\otimes)$

Shock Wave Laboratory, RWTH Aachen University,

Schurzelterstr. 35, 52074 Aachen, Germany

e-mail: olivier@swl.rwth-aachen.de

S. Ludescher

e-mail: ludescher@swl.rwth-aachen.de

(C) The Author(s) 2021 
of film cooling behavior under these conditions. This is done by performing an experimental parametric study in the expansion part of a conical nozzle. A thoroughly validation of the nozzle flow showed a good similarity of the flow in the conical nozzle and the flow in a real engine. Additionally, a theoretical film cooling model based on the common Goldstein model [2] and a method for calculating the cooling efficiencies from the measured wall heat fluxes was developed. Based on this, a well-fitting correlation of the experimental data was found and a simple model for estimating the needed coolant mass fluxes for a film cooling application in a nozzle is given. For further application of film cooling in novel nozzle concepts, film cooling experiments in a dual-bell nozzle were conducted. The aim of these investigations was an evaluation of the influence of the contour inflection geometry on the film cooling efficiency in the bell extension of a dual-bell nozzle operating in altitude mode. All these results can support future design processes of film cooling in rocket nozzles.

\section{Film Cooling Theory}

In this project supersonic, tangential film cooling in a supersonic nozzle flow is investigated. Further, the following assumptions are valid: The coolant is gaseous, the nozzle hot gas and the coolant gas are not identical, the coolant gas is much cooler than the hot gas and the coolant Mach number and velocity is lower than that of the hot gas. A general schema for the coolant- hot gas interaction at the injection position is given in Fig. 1.

The first mixing of coolant and hot gas occurs in the mixing layer or shear layer, which starts to grow at the tip of the splitter plate. Since underneath this layer a region of pure coolant gas exists the wall heat fluxes here are assumed to be dominated by the coolant gas temperature. After a certain distance from the injection position the mixing layer reaches the nozzle wall. Starting at this point, the wall heat fluxes are dominated by the local coolant-hot gas mixture.

Fig. 1 Schematic interaction of hot gas and overexpanded coolant at the injection position for tangential injection, shocks and expansion waves are not shown

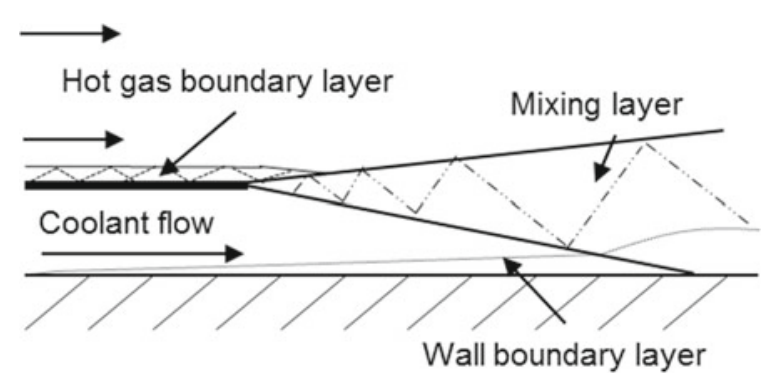




\subsection{Film Cooling Efficiency}

The cooling efficiency is defined by the ratio of the reached wall temperature reduction in case of coolant injection to the maximum, theoretical possible wall temperature reduction.

$$
\eta=\frac{T_{r}-T_{a w, c}}{T_{r}-T_{0, c}}
$$

with $T_{r}$ the recovery temperature of the hot gas, $T_{0, c}$ the coolant stagnation temperature and $T_{a w, c}$ the adiabatic wall temperature in case of coolant injection. Assuming isothermal wall conditions $\left(T_{w}=\right.$ const . $)$ and $T_{w}=T_{0, c}$, the cooling efficiency can be rewritten as [5]

$$
\eta=1-\frac{\alpha_{\infty} \dot{q}_{m}}{\alpha_{m} \dot{q}_{\infty}}
$$

Here, $\eta$ is a function of the wall heat fluxes $\dot{q}$ measured in the experiment and the heat transfer coefficients $\alpha$ of hot gas $\infty$ and hot gas-coolant mixture $m$. Since it is not feasible to determine the ratio of the heat transfer coefficients experimentally, this ratio was often assumed to be one in previous projects [5, 13]. To check this assumption, numerical simulations for film cooling in the conical nozzle with different coolant gases and blowing ratios were performed and the cooling efficiencies without the ratio of the heat transfer coefficients (Fig. 2) and with the real ratio of the heat transfer coefficients (Fig. 3) were calculated.

Comparing Figs. 2 and 3 a strong influence of the heat transfer coefficients on not only the total value of the cooling efficiencies but also on the coolant specific cooling efficiency relative to the other gases can be seen. Therefore, a method for calculating the heat transfer ratio in Eq. 2 was developed (see [7]):

$$
\frac{\alpha_{\infty}}{\alpha_{m}}=\frac{x_{m} \lambda_{\infty} \operatorname{Pr}_{\infty}^{0.43} \operatorname{Re}_{\infty}^{0.8}}{x_{\infty} \lambda_{m} \operatorname{Pr}_{m}^{0.43} \operatorname{Re}_{m}^{0.8}}
$$

Fig. 2 Cooling efficiency with $\frac{\alpha_{\infty}}{\alpha_{m}}=1$

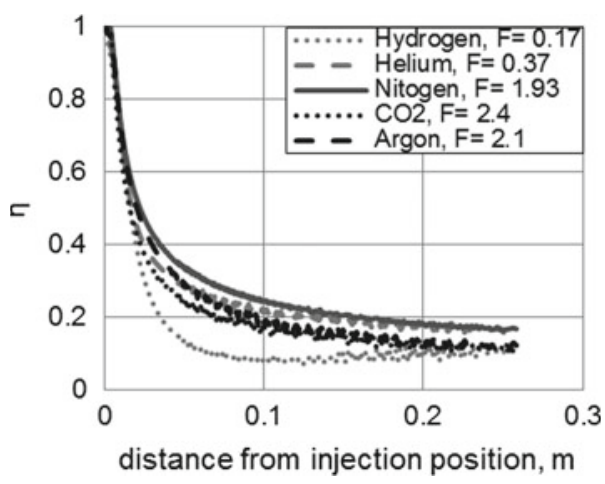


Fig. 3 Cooling efficiency with $\frac{\alpha_{\infty}}{\alpha_{m}} \neq 1$

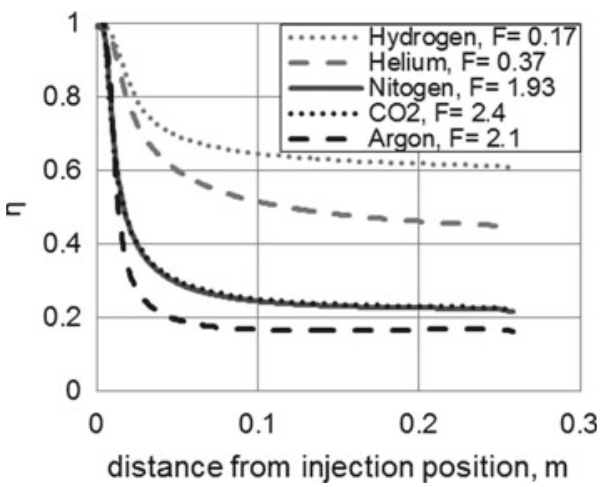

with the distance from the injection point $x$, the thermal conductivity $\lambda$, the Prandtl number $\mathrm{Pr}$ and the Reynolds number $R e$.

\subsection{Film Cooling Model}

For describing the mixing of hot gas and coolant at the wall an axisymmetric film cooling model based on Goldstein's mixing model [2] was developed by Ludescher et al. (see [7]). In this model the amount of hot gas mixing up with the coolant is assumed to be equal to the mass flux in a fictitious boundary layer starting to grow at the injection point. A sketch of the boundary layer growth in the nozzle can be seen in Fig. 4.

Due to the increasing nozzle diameter of the nozzle extension the mixing hot gas mass flux $\dot{m}_{\infty}$ grows not only with the height of the boundary layer but also with the increasing nozzle radius. Using Goldstein's definition of the cooling efficiency $\eta$
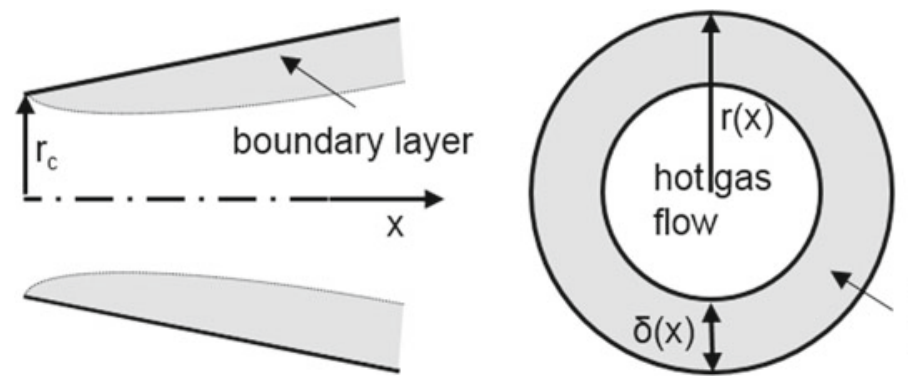

mixing hot gas mass flux $\dot{m}_{\infty}$

Fig. 4 Axisymmetric mixing model 


$$
\eta=\left[1+\frac{c_{p, \infty}}{c_{p, c}} \frac{\dot{m}_{\infty}}{\dot{m}_{c}}\right]^{-1}=\left[1+\frac{c_{p, \infty}}{c_{p, c}} \xi\right]^{-1}
$$

the correlation factor $\xi$ for the axisymmetric case is given by

$$
\xi=\frac{7 \delta(x) r(x)}{8 F s r_{c}} .
$$

This factor depends on the local nozzle radius $r(x)$, the blowing ratio $F=\frac{\rho_{c} u_{c}}{\rho_{\infty} u_{\infty}}$, the injection slot height $s$, the nozzle radius at the point of injection $r_{c}$ and the local boundary layer height of the hot gas $\delta(x)$ starting to grow at the injection point. Accounting for the compressibility and pressure gradient of the nozzle flow the boundary layer height is calculated using the model by Stratford and Beavers [11]

$$
\begin{array}{r}
\delta(x)=0.376 X \operatorname{Re}^{-0.2} \\
X=P(x)^{-1} \int_{0}^{x} P(x) d x \\
P(x)=\left[\frac{\operatorname{Ma}(x)}{1+\frac{\gamma-1}{2} \operatorname{Ma}(x)^{2}}\right]^{4} .
\end{array}
$$

\section{Experimental Setup}

\subsection{Test Facility}

All experimental investigations were conducted using a detonation based shortduration facility (see [12]). This facility provides a hydrogen-oxygen combustion hot gas with high stagnation pressures and temperatures for an effective testing time of about 4-7 ms. By changing the initial state of the detonation different hot gas conditions can be achieved. Due to this short testing time, the facility walls are assumed to be isothermal. A heating system to heat the walls up to the saturation temperature of water vapour was applied [3] to avoid condensation of the gaseous water at the facility walls. The hot gas conditions used for the experimental investigations are listed in Table 1.

These are the stagnation conditions for the flow in the nozzle, which is attached to the detonation tube. 
Table 1 Hot gas conditions (based on [12])

\begin{tabular}{l|l|l|l}
\hline & Condition 1 & Condition 2 & Condition 3 \\
\hline$T_{0}$ & $3660 \mathrm{~K}$ & $3685 \mathrm{~K}$ & $3630 \mathrm{~K}$ \\
\hline$p_{0}$ & $30 \mathrm{bar}$ & $40 \mathrm{bar}$ & $50 \mathrm{bar}$ \\
\hline ROF & 8 & 8 & 8 \\
\hline$T_{\text {wall }}$ & $330 \mathrm{~K}$ & $340 \mathrm{~K}$ & $350 \mathrm{~K}$ \\
\hline
\end{tabular}

\subsubsection{Conical Nozzle ${ }^{1}$}

The parametric study on film cooling took place in a conical nozzle (see Fig. 5).

Wall heat fluxes and static pressures are measured in the nozzle extension using thermocouples type E and Kulite pressure transducers. Further details of the nozzle are given in Table 2.

\subsubsection{Dual-Bell Nozzle}

For investigating the influence of the contour inflection geometry on the coolant film behavior a dual-bell nozzle with exchangeable contour inflection geometry was designed and built. Due to practical reasons as much of the conical nozzle setup as possible was reused in the design process of the dual-bell nozzle. Therefore, the base nozzle segment was chosen to be a shorter version of the conical nozzle. The bell extension of the nozzle was designed by Dr. Chloé Génin ${ }^{2}$ assuming hot gas condition 1 and a nozzle operation in altitude mode. The final nozzle can be seen in Fig. 6.

As contour inflection geometries a sharp-edge and a rounded geometry were chosen, because here the biggest differences in the shape of the expansion fan at the inflection point are expected. Further details of the dual-bell nozzle are listed in Table 3.

As the conical nozzle the dual-bell nozzle is instrumented with thermocouples type $\mathrm{E}$ and Kulite pressure transducers.

\subsubsection{Coolant Supply}

For tangential coolant gas injection a circumferential injection slot is placed in the nozzle extension. Due to the laval nozzle like shape of the injection slot the coolant flow is accelerated to supersonic speed. The coolant mass flux is controlled by a venturi nozzle. The coolant supply and injection system is the same for both nozzles. A schematic sketch of the supply system can be seen in Fig. 7.

\footnotetext{
${ }^{1}$ The experimental setup of the conical nozzle was designed by Mr. Yahiaoui see [13].

${ }^{2}$ Project K2 of SFB TRR 40.
} 


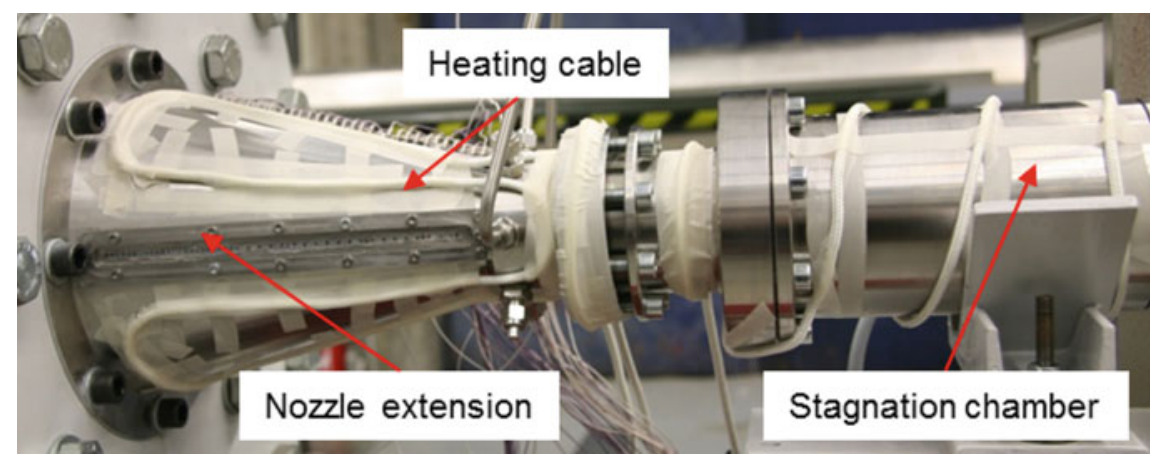

Fig. 5 Conical nozzle with heating system and stagnation chamber

Table 2 Details of the conical nozzle [13]

\begin{tabular}{l|l}
\hline Expansion part length & $340 \mathrm{~mm}$ \\
\hline Throat diameter & $15.96 \mathrm{~mm}$ \\
\hline Half opening angle & $15^{\circ}$ \\
\hline
\end{tabular}
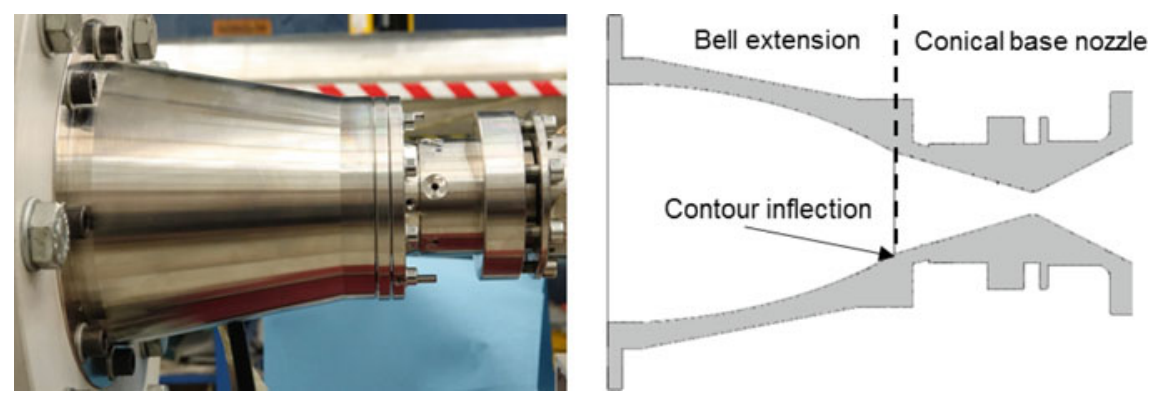

Fig. 6 Dual-bell nozzle at the test facility (left) and section view of the nozzle (right)

Table 3 Details of the dual-bell nozzle

\begin{tabular}{l|l}
\hline Nozzle pressure ratio, NPR & 160 \\
\hline Inflection angle & $10.6^{\circ}$ \\
\hline Extension length & $199.12 \mathrm{~mm}$ \\
\hline Base length & $104.21 \mathrm{~mm}$ \\
\hline $\begin{array}{l}\text { Distance between coolant injection and contour } \\
\text { inflection }\end{array}$ & $19.9 \mathrm{~mm}$ \\
\hline
\end{tabular}




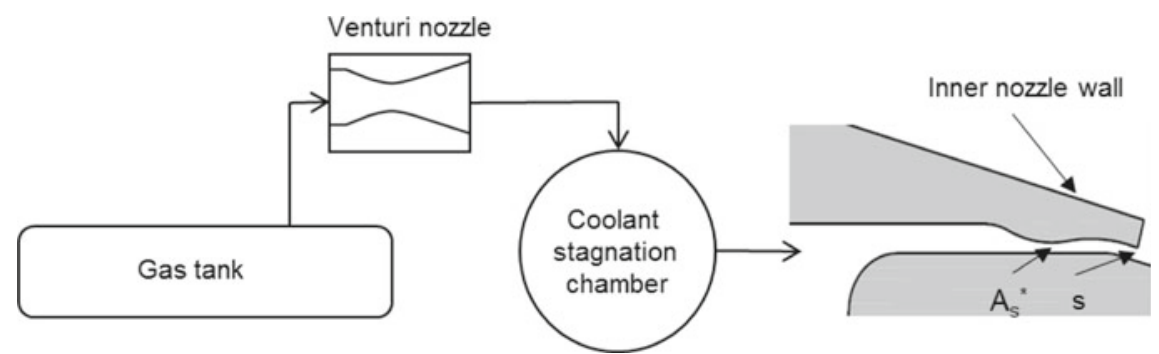

Fig. 7 Schema of coolant supply system

Table 4 Coolant injection details (for details of the coolant supply setup of the conical nozzle see [13])

\begin{tabular}{l|l|l}
\hline & Conical nozzle & Dual-bell nozzle \\
\hline Slot height $(\mathrm{s} 1, \mathrm{~s} 2, \mathrm{~s} 3)$ & $0.46,0.41,0.56 \mathrm{~mm}$ & $0.46 \mathrm{~mm}$ \\
\hline Splitter thickness & $1 \mathrm{~mm}$ & $1 \mathrm{~mm}$ \\
\hline $\begin{array}{l}\text { Distance between } \\
\text { injection position }\end{array}$ & $87 \mathrm{~mm}$ & $87 \mathrm{~mm}$ (end of base nozzle) \\
\hline
\end{tabular}

The injection slot is exchangeable in every nozzle such that different slot heights can be applied. For the presented setup three different slots are available (see Table 4).

To allow for experiments without coolant injection a disturbance free flow the injection slot can be replaced by an insert, which provides a smooth inner nozzle wall contour [13].

\section{Results Conical Nozzle}

\subsection{Reference Flow}

First, experiments without film cooling were conducted. Here, the wall heat flux and static pressure distribution along the nozzle wall for every hot gas condition (see Table 1) were measured. Furthermore, RANS simulations with ANSYS Fluent were conducted, which took into account the chemical behavior of the flow [7]. Based on the comparison of the experimental and numerical results the assumption of a turbulent boundary layer and a chemical frozen state of the flow close behind the nozzle throat is confirmed [7]. A comparison of experimental and numerical wall heat fluxes for each condition is shown in Fig. 8. 
Fig. 8 Experimental and numerical wall heat flux distribution for all three hot gas conditions

Fig. 9 Wall heat flux distribution without (reference) and with carbon dioxide injection $(\mathrm{F}=3.6)$
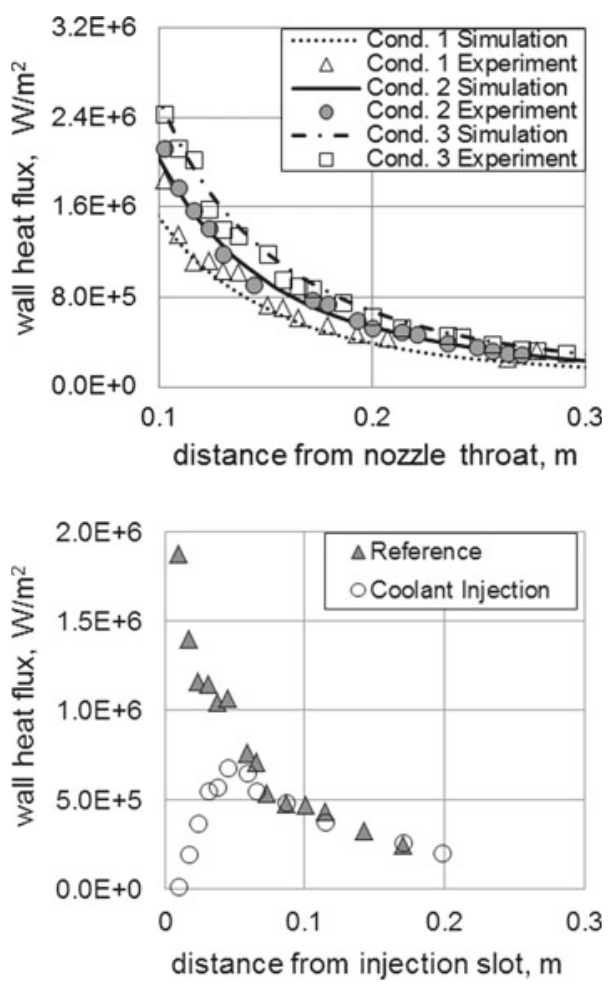

\subsection{Parametric Study}

As next step coolant gas was injected. Figure 9 shows exemplary for carbon dioxide as coolant gas a comparison of wall heat flux with and without coolant injection. The strong cooling effect of the injected gas shortly downstream of the injection slot is clearly visible by the strong heat flux reduction. The measured heat fluxes with and without cooling allow to determine the cooling efficiency according to Eq. (2). With a parametric study the influence of various parameter on film cooling efficiency were investigated. Therefore, the injection conditions, the hot gas conditions and the coolant gas were separately changed [7]. The qualitative findings of this study are listed in Table 5.

\subsection{Correlation}

In the following the axisymmetric film cooling model and the method for calculating the film cooling efficiencies (see Eqs. (2) and (5)) were used to correlate the data gained in the parametric study. As can be seen in Fig. 10 a good correlation of the experimental data is reached. 
Table 5 Influence of an increasing parameter (left) on the cooling efficiency (right) [7, 8]

\begin{tabular}{l|l}
\hline Parameter & $\eta$ \\
\hline Coolant mass flux & Increases \\
\hline Slot height & Increases \\
\hline Mach number coolant & Increases \\
\hline Heat capacity coolant & Increases \\
\hline Prandtl number coolant & Decreases \\
\hline Molar mass coolant & Decreases \\
\hline Injection pressure coolant & Increases \\
\hline Distance from injection point & Decreases \\
\hline Blowing ratio & Increases \\
\hline Momentum flux ration & Increases \\
\hline Convective Mach number & No influence
\end{tabular}

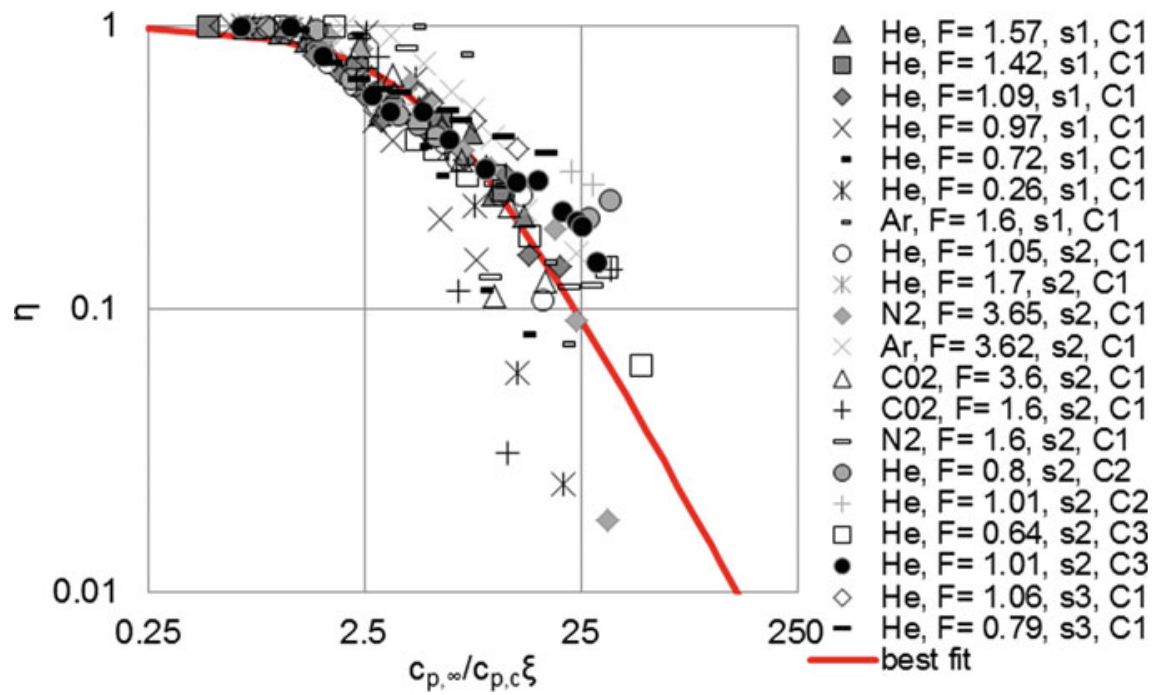

Fig. 10 Correlation of the experimental data, red curve refers to Eq.9

The resulting curve is fitted by

$$
\eta=\frac{1}{1+0.1101\left(\frac{c_{p, \infty}}{c_{p, c}} \xi\right)^{1.3934}}=\frac{T_{r}-T_{a w, c}}{T_{r}-T_{0, c}} .
$$

This equation can be used as a design tool for film cooling in nozzles i.e. to mainly determine the adiabatic wall temperature in case of cooling. However, it has to be mentioned that this correlation was derived for the subscale, conical nozzle with isothermal walls and gaseous coolants. The applicability of this correlation on a real engine may be restricted. 


\section{Results Dual-Bell Nozzle}

For investigating the influence of the inflection point geometry on the hot gas and coolant flow behavior experiments without and with coolant injection for the sharpedge and rounded adapter configuration of the dual-bell nozzle were conducted.

\subsection{Experiments Without Film Cooling}

First, experiments without film cooling were conducted to compare the hot gas flow behavior for the different contour geometries. Figure 11 shows the static pressure distributions and Fig. 12 the wall heat flux distributions along the distance from the nozzle throat for the sharp-edge and rounded contour configuration. For the static pressures, no relevant deviation in the data is visible. In contrast to that, a more systematic deviation between the wall heat fluxes of sharp-edge and rounded configuration can be seen.

Fig. 11 Comparison of static pressure distribution for the sharp-edge and rounded configuration, hot gas condition 1 , red dashed lines represent the inflection region

Fig. 12 Comparison of wall heat flux distribution for the sharp-edge and rounded configuration, hot gas condition 1, red dashed lines represent the inflection region
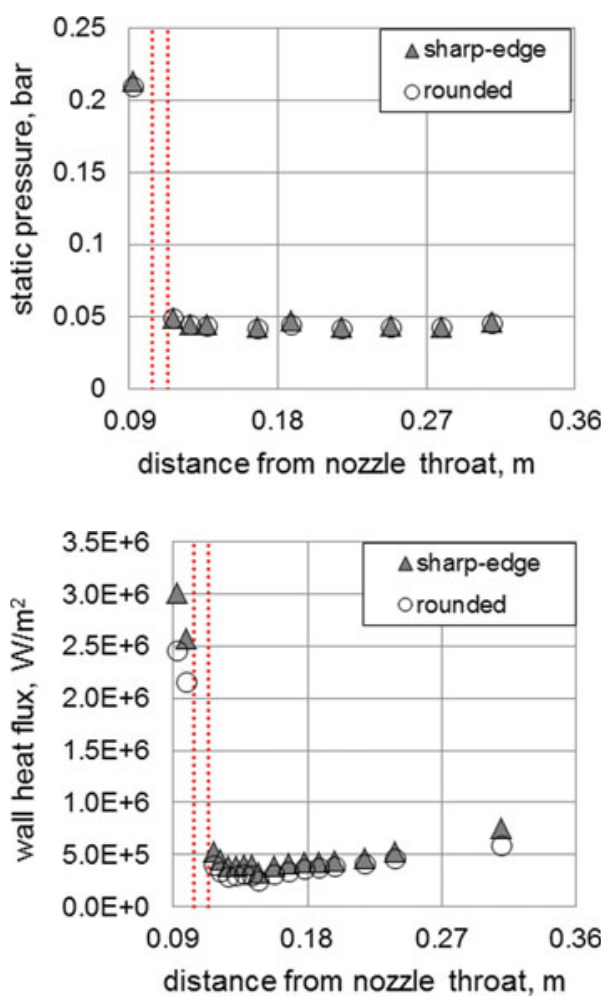
The heat fluxes for the sharp-edge are about $20 \%$ higher than for the rounded inflection contour. This confirms findings by Génin and Stark [1]. It may result from the differences in the expansion fan and the local flow acceleration, which leads to differences in the boundary layer height.

\subsection{Experiments with Film Cooling}

Following, experiments with helium injection were conducted. For comparing the results, the cooling efficiencies of each experiment were calculated using Eq. 2 assuming $\frac{\alpha_{\infty}}{\alpha_{m}}=1$. The resulting curves of the cooling efficiencies for three different blowing ratios are displayed in Figs. 13 and 14.

For all blowing ratios the cooling efficiencies for the sharp-edge configuration are higher than the ones for the rounded configuration. A reason for this might be the locally stronger acceleration of the cooling film due to the centred expansion fan. This fits also to a study by Martelli et al. [9], showing that the expansion of the coolant

Fig. 13 Comparison of cooling efficiencies for helium injection $\mathrm{F}=1.37$ (for both configurations), red dashed lines represent the inflection region

Fig. 14 Comparison of cooling efficiencies for helium injection $\mathrm{F}=0.73$ (sharp-edge) and $\mathrm{F}=0.72$ (rounded), red dashed lines represent the inflection region
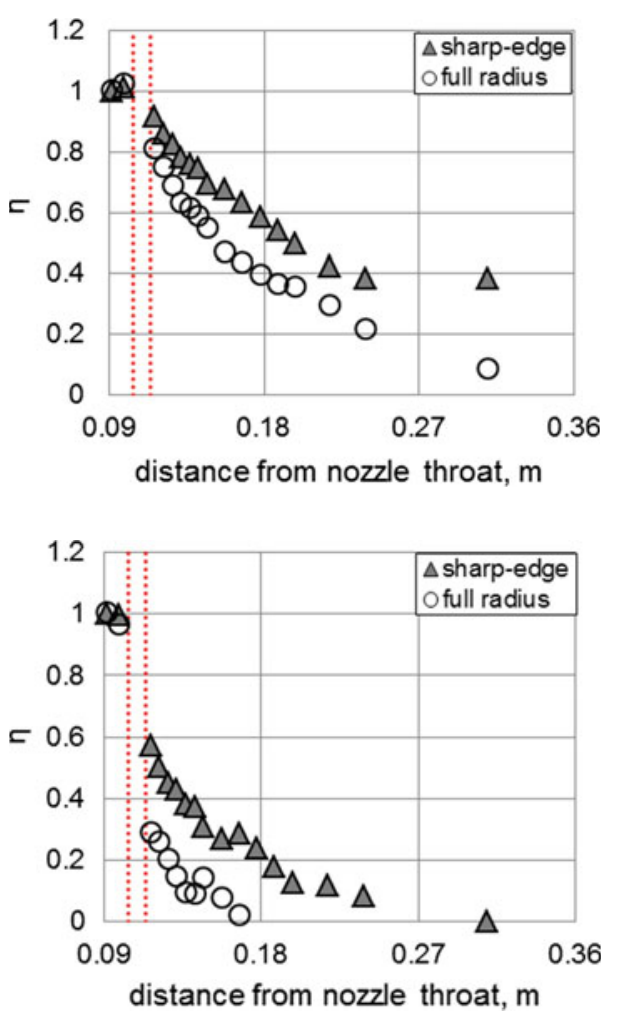
film can lower the mixing rate of hot gas and coolant. Thus a sharp-edge contour inflection is recommended for film cooling application in the dual-bell nozzle.

\section{Conclusion}

In this work supersonic, tangential film cooling in a conical and a dual-bell nozzle was investigated. The used hot gas conditions of the nozzle flow were similar to the conditions in a real rocket nozzle. A parametric study of film cooling was conducted in the expansion part of the conical nozzle. As most important influencing parameters for this setup, the mass flux, Mach number, Prandtl number, molar mass and injection pressure of the coolant as well as the distance from the injection point and the height of the injection slot were found. A theoretical model for film cooling based on the Goldstein model was developed. Additionally, a method for estimating the heat transfer coefficients in the experiments was presented. Using this and the new film cooling model, a well fitting correlation of the experimental data was achieved, which can be used in future design processes of film cooled nozzles. Further, the film cooling behavior at the inflection point of a dual-bell nozzle was investigated. A clear influence of the inflection geometry on the wall heat fluxes in the nozzle was shown. For a sharp-edge contour inflection the cooling efficiency in the bell extension was found to be much higher than for a rounded contour inflection over the whole range of investigated blowing ratios. Therefore, a sharp-edge contour inflection is recommended for film cooled dual-bell nozzles.

Acknowledgements Financial support has been provided by the German Research Foundation (Deutsche Forschungsgemeinschaft- DFG) in the framework of the Collaborative Research Center/Transregio 40 and is gratefully acknowledged by the authors. The authors would also like to thank Mr. Cavdir for performing the numerical simulations and Mr. Ziay-Nikpour for the final elaboration of the construction of the dual-bell nozzle.

\section{References}

1. Génin, C., Stark, R.: Experimental investigation of the inflection geometry on dual bell nozzle flow behaviour. In: 47th AIAA/ASME/SAE/ASEE Joint Propulsion Conference and Exhibit, AIAA 2011-5612, (2011). https://doi.org/10.2514/6.2011-5612

2. Goldstein, R.J.: Film cooling. Advances in Heat Transfer, vol. 7, pp. 321-379 (1971)

3. Haase, S., Olivier, H.: Influence of condensation on heat flux and pressure measurements in a detonation-based short-duration facility. Exp. Fluids 58(10), 137 (2017). https://doi.org/10. 1007/s00348-017-2419-6

4. Hagemann, G., Ryden, R., Frey, M., Stark, R., Alting, J.: The calorimeter nozzle programme. In: 38th AIAA/ASME/SAE/ASEE Joint Propulsion Conference and Exhibit, AIAA 2002-3998 (2002). https://doi.org/10.2514/6.2002-3998

5. Heufer, K.A., Olivier, H.: Experimental and numerical study of cooling gas injection in laminar supersonic flow. AIAA J. 46(11), 2741-2751 (2008). https://doi.org/10.2514/1.34218 
6. Kercher, D.M.: A film-cooling CFD bibliography: 1971-1996. Int. J. Rotating Mach. 4(1), 61-72 (1998). https://doi.org/10.1155/S1023621X98000062

7. Ludescher, S., Olivier, H.: Experimental investigations of film cooling in a conical nozzle under rocket-engine-like flow conditions. AIAA J. 57(3), 1172-1183 (2019). https://doi.org/ 10.2514/1.J057486

8. Ludescher, S., Olivier, H.: Use of a detonation tube for investigation of the mixing effects of hot gas and coolant in a film cooled nozzle. In: 32nd International Symposium on Shock Waves (ISSW), National University of Singapore, Sinpapore (2019)

9. Martelli, E., Nasuti, F., Onofri, M.: Effect of wall shape and real gas properties on dual bell nozzle flowfields. In: 41st AIAA/ASME/SAE/ASEE Joint Propulsion Conference and Exhibit, AIAA 2005-3943 (2005). https://doi.org/10.2514/6.2005-3943

10. Shine, S.R., Nidhi, S.S.: Review on film cooling of liquid rocket engines. Propuls. Power Res. 7(1), 1-18 (2018). https://doi.org/10.1016/j.jppr.2018.01.004

11. Stratford, B.S., Beavers, G.S.: The Calculation of the Compressible Turbulent Boundary Layer in an Arbitrary Pressure Gradient: A Correlation of Certain Previous Methods. Aeronautical Research Council, Reports and Memoranda No. 3207, Ministry of Aviation, London, UK (1961)

12. Yahiaoui, G., Olivier, H.: Development of a short-duration rocket nozzle flow simulation facility. AIAA J. 53(9), 2713-2725 (2015). https://doi.org/10.2514/1.J053790

13. Yahiaoui, G.: Film cooling investigations for rocket nozzle flows with a new test facility technique. Dissertation, RWTH Aachen University (2018)

Open Access This chapter is licensed under the terms of the Creative Commons Attribution 4.0 International License (http://creativecommons.org/licenses/by/4.0/), which permits use, sharing, adaptation, distribution and reproduction in any medium or format, as long as you give appropriate credit to the original author(s) and the source, provide a link to the Creative Commons license and indicate if changes were made.

The images or other third party material in this chapter are included in the chapter's Creative Commons license, unless indicated otherwise in a credit line to the material. If material is not included in the chapter's Creative Commons license and your intended use is not permitted by statutory regulation or exceeds the permitted use, you will need to obtain permission directly from the copyright holder.

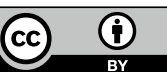

